\section{Vietnam Journal of Agricultural Sciences}

\title{
The Impacts of Climate Change on Agricultural Production and Sustainable Agriculture of Smallholder Farmers in Vietnam
}

\author{
Nguyen Van Phu
}

Faculty of Agronomy, Vietnam National University of Agriculture, Hanoi 131000, Vietnam

\begin{abstract}
Climate change is one of the greatest threats to human beings, and agriculture is one of the fields that is most negatively affected by climate change. Farmers around the world and global food supply chains are impacted by the more extreme weather phenomena and increased damage of diseases and pests caused by climate change. Today, almost all agricultural enterprises and farms consider climate change a serious long-term risk for their production. Agricultural land systems can produce significant greenhouse gases (GHGs) by the conversion of forests to crop and animal lands, and also through the weak management of crops and livestock. Around the world, cultivation and cattle production accounts for $25 \%$ of global GHG emissions (Javeline, 2014). However, under suitable conditions, agriculture can create environmental conditions that can help minimize pollution and the negative effects of climate change including carbon absorption by green plants in forests, and fields for watershed protection and biodiversity conservation. Sustainable agriculture helps farmers to adapt, maintain, and improve productivity without applying harmful techniques. In turn, this allows farms to manage and mitigate climate-related risks in their supply chains. The Sustainable Agriculture Network (SAN) has found new ways to incorporate smart climate cultivation methods into all farming practices to help farms and enterprises carry out agriculture sustainably.
\end{abstract}

\section{Keywords}

Climate change, sustainable agriculture, farmers and production

\section{The Definition and Reasons for Climate Change}

Received: November 15, 2020 Accepted: April 22, 2021

\section{Correspondence to} nvphu@vnua.edu.vn
According to the U.S. National Aeronautics and Space Administration (NASA, 2014), climate change is an unusual weather change in a place. Climate change can be a change in the amount of rain or drought a place usually gets in a year, or it can be a change 
in a place's usual temperatures (higher or lower) over a month or season in big or small areas around the world.

Many factors can cause climate change but there are two main categories of climate change. The first category relates to changes in nature, including changes in the activities of the sun (Xiao et al., 2017), changes of Earth's orbit (NASA, 2014), changes of the locations and scale of the continents, and changes in oceanic patterns (NASA, 2020). The second category comes from human activities, such as changes in land when forestland is converted to cultivated land or grazing land, changes in water use purposes (FAO, 2020) such as dumps for electronics, and increases in $\mathrm{CO} 2$ emissions and other greenhouse gases from human activities from industrialization, urbanization, transportation, and so on. The world's $\mathrm{CO} 2$ emissions in 2014 reached 36,669,000.00 tons per year, an average of 5 tons per capita, and among the world's countries, the highest emissions rate was in China with more than 10 million tons, followed by the U.S. with more than 5 million tons (Netherlands Environmental Assessment Agency, 2015). In Vietnam, the total greenhouse gas (GHG) rate was 283,965.53 tons by 2014 , in which, transportation and energy accounted for $53.8 \%$, agriculture accounted for $27.92 \%$, industries and consumptions accounted for $12.1 \%$, and other fields accounted for $6.69 \%$ (Ministry of Natural Resources and Environment, 2014).

\section{The Overall Effects of Climate Change}

The destroying effects of climate change could be considered the most concerning problem as climate change has led to global high temperatures, melting ice, rising sea levels, and extreme weather phenomena such as floods, tsunamis, earthquakes, droughts, and prolonged cold leading to lack of food events, starvation, and a mass of epidemics affecting humans, cattle, and poultry. According to FAO (2018), 200 million people around the world will live below the sea level line by 2100 , and an additional 160 million will be affected by higher annual flooding due to rising ocean levels (FAO, 2020).
These numbers are much higher than those published in previous studies and the predicted timeline is shorter. The prediction software used different coastal elevation models and assumed that only 250 million people in total would be affected by these adverse events (FAO, 2018). Southern European countries are facing the risk of more frequent serious droughts that easily cause wildfires and desertification, while Western European countries are suffering from floods coming from the rising sea levels as well as harsh winter frosts. Big storms have occurred in the United States, China, Japan, and India caused by global warming in the last several decades. Yearly data taken by satellites show that the number of storms has not changed but the number of tornadoes and storms with strong intensities and causing great devastation has increased yearly, especially in North America, the Southwest Pacific, Indian Ocean, and North Atlantic Ocean (NASA, 2020).

\section{The Effects of Climate Change on Agriculture}

Not only is agriculture the main field of human society threatened by climate change, as it is impacted by extreme climate phenomena like storms, floods, droughts, and diseases that damage crop yield, but it is also a key force of environmental and climate change because it has the largest human impact on changes to land and water resource purposes. Approximately 1.6 billion hectares of arable land (around $12.5 \%$ of the total ice-free land) is used for crops (FAO, 2018). Agriculture is also a main sector of water use. In 2010, more 300 million hectares of arable land was irrigated, corresponding to about $70 \%$ of freshwater resources withdrawn from aquifers, lakes, and rivers, and by other human activities (FAO, 2018).

Agriculture accounts for more than $25 \%$ of carbon dioxide, $50 \%$ of methane, and $75 \%$ of nitrous oxide emissions annually produced by human activities (NASA, 2018). But agriculture is one of the areas that can contribute to both reducing greenhouse gas emissions and minimizing $\mathrm{CO}_{2}$ emissions through sustainable production practices, as trillions of tons of $\mathrm{CO}_{2}$ 
have been taken up by plants yearly during photosynthesis in green plants (Lincoln, 1999).

Climate change strongly affects agriculture, and there are five main effects on agriculture. First, floods and sea-level rise will lead to the loss of agricultural soil due to increases in soil salinity. For example, in Vietnam, if the sea level rises by $1 \mathrm{~m}$ and there are no effective preventive techniques, about $40 \%$ of the Mekong Delta (MRD), $11 \%$ of the Red River Delta (RRD), and $3 \%$ of the other coastal provinces will be flooded in the near future. Floods will cause about $50 \%$ of the agricultural land in the Mekong Delta to be submerged and unusable for cultivation. According to the World Resources Institute's analysis of the impact of floods on GDP, Vietnam ranked fourth among the 164 countries evaluated in terms of the serious impact floods will have on the economy and society, and predicted damage of $2.3 \%$ of Vietnam's GDP yearly (Institute of Meteorology, Hydrology and Climate Change, 2018).

Second, saline pollution in coastal areas will also reduce the area of cultivated soil. A significant portion of farming soil in the Red River Delta and the Mekong Delta will be saline. Saline pollution makes the area of arable land decrease, so the coefficient of land use could decrease from 3-4 times per year to 1-1.5 times per year. If the sea level rises by $1 \mathrm{~m}$, about 1.77 million hectares of land will become salinated, accounting for $45 \%$ of the land area in the Mekong Delta, and it has been calculated that about $85 \%$ of people in the Mekong Delta will need agricultural support (Ministry of Natural Resources and Environment, 2014a; b; 2017).

Third, high temperatures and drought conditions will also threaten the distribution of crop production, especially reducing yields. Specifically, the rice yields of the summer season tend to decrease more sharply than yields of the spring crop due to high temperatures, and in the winter, maize production tends to increase in the Northern Delta and decrease in the Central and Southern regions due to low temperatures. So, if there is no immediate response, the efficiency of rice production in the RRD region could be reduced by $3.7 \%$ in 2020 and down to $16.5 \%$ in 2070 , and the lost agricultural land and declining crop yields will cause more challenges and threats to farmers' livelihoods, national food security, and rice exports in a country where agriculture plays an important role in the national economy (Ministry of Natural Resources and Environment, 2017).

Fourth, climate change will also directly affect fishing areas. Vietnam currently has about 480,000 people who directly take part in fishing and aquaculture, 100,000 people who work in the seafood processing industry, and about $2,140,000$ people who rely on fishing services. Fishing and farming are the two main sectors that depend on water resources and the abundance of coastal resources, and the coastal regions are the most sensitive and vulnerable areas affected by the negative effects of climate change (Ministry of Rural Development and Agriculture, 2018).

Fifth, climate change will impact natural forest resources and ecosystems. Over the past few decades, due to various reasons, biodiversity and ecosystems, especially the natural forest ecosystems, have been seriously degraded because (i) the rise of sea levels has reduced the area of coastal submerged forests adversely affecting the ecology of Melaleuca forests and plantations due to acid sulfate soil in the Mekong Delta; (ii) increased global warming temperatures have led to more evaporation of water causing prolonged drought, which continues to affect the growth ability of forest plants and animals; and (iii) Vietnam loses a large areas of land annually due to forest fires caused by climate change and exploration of forests for food, wood, and other purposes, so many pests, animals, plants, and even the local varieties of crops and animals are extended by these activities.

\section{Human responses to climate change}

Humans have shown a variety of responses to cope with climate change. There are two main ways that humans can respond to climate changes: mitigation and adaptation.

First, reducing the negative effects of climate change involves reducing the flow of 
heat-trapping greenhouse gases into the atmosphere by reducing the sources of these gases (for example, the burning of fossil fuels for electricity, heat, or transportation) or fortifying the "sinks" that concentrate and store these gases (such as oceans, forests, farms, and soil) (NASA, 2020). The goal of mitigation is to avoid significant human interference with the climate system, and "stabilize greenhouse gas levels in a time frame sufficient to allow ecosystems to adapt naturally to climate change, ensure that food production is not threatened, and to enable economic development to proceed sustainably" (Javeline, 2014). Specificity, in the agriculture field, mitigation might include reducing emissions because agriculture activities release to the atmosphere significant amounts of $\mathrm{CO}_{2}$, $\mathrm{CH}_{4}$, and other chemicals that come from using fertilizers, herbicides, and pesticides. These gases can be reduced by more efficient management of carbon and nitrogen flows in agricultural ecosystems and by efficiently using the inputs of agriculture, leading to less carbon dioxide, nitrogen, and methane released. The next strategy to consider is avoiding or displacing emissions allowing the energy efficiency of the agriculture sector can be improved. For example, fossil fuel energy used in agricultural production can in some cases be replaced with biofuels and renewable energy such as sunlight, wind, and tide energy. Greater use of wood products can also lead to displacing $\mathrm{CO}_{2}$ emissions. GHGs can be absorbed from the atmosphere through sinks. A sink is any process, activity, or mechanism that removes a greenhouse gas, an aerosol, or a precursor of greenhouse gas or aerosol from the atmosphere (FAO, 2019; NASA, 2020).

Second, adapting to life in a changing climate involves adjusting to the actual or expected future climate (FAO, 2019). The goal is to reduce our vulnerability to the harmful effects of climate change like sea-level encroachment, more intense and extreme weather events, or food insecurity (Sierra-Correa \& Kintz, 2015). It also encompasses making the most of any potential beneficial opportunities associated with climate change (for example, longer growing seasons or increased yields in some regions)
(NASA, 2020). In the agriculture area, the best way to respond to climate change involves adaptation strategies that are a combination of specific actions such as the creation of new varieties of crops and animals to respond to stress conditions (drought, salinity, and diseases, etc.), diversifying human livelihoods against risks along with institutional reforms to create incentives for better resource management, and the reduction of the overconsumption of goods by humans (Shaffril et al., 2018).

\section{Definition of sustainable agriculture}

Agriculture plays one the most important roles in the economies of developing countries and provides the main source of food, income, and employment for the rural populations in many countries in Asia, South America, and Africa. It has been established that in Vietnam, $67 \%$ of the total populace works in the agricultural sector, agriculture accounts for $39.4 \%$ of the GDP, and $43 \%$ of all exports consist of agricultural goods (FAO, 2018). Thus, one Vietnam's goals is to develop and implement sustainable agriculture and crop production methods without damaging the environment or contributing to climate change. Sustainable agriculture is an integrated system of plant and animal production practices focusing on sitespecific applications that will, over the long term: (i) satisfy human needs for food and other goods; (ii) protect and upgrade environmental quality for offspring; (iii) make efficient use of nonrenewable and renewable resources and integrate appropriate natural biological cycles and controls; (iv) stabilize the economic viability of farm operations; and (v) improve the quality of life of farmers and society as a whole.

\section{Main objectives of the Sustainable Agriculture Network}

The reduction of GHG is a main objective for every country all over the world. China has stated that they are committed to cutting $60-70 \%$ of their $\mathrm{CO}_{2}$ emissions corresponding to more than 6 million tons, followed by America cutting of $50 \%$ of their $\mathrm{CO}_{2}$ emissions corresponding to 
more than 2.5 million tons (Netherlands Environmental Assessment Agency, 2015). Vietnam has also committed to reducing $\mathrm{CO}_{2}$ emissions by $27 \%$ by 2030 (Ministry of Natural Resources and Environment, 2014).

The Sustainable Agriculture Network (SAN) is a group of organizations around the world who's sustainable agriculture approach focuses on building resilient agroecosystems and reducing the harmful impacts of agricultural activities on the environment by developing agriculture production methods that restore and increase natural and artificial carbon traps such as photosynthesis in green plants. An agricultural ecosystem is an ecosystem associated with human development. A healthy agricultural ecosystem provides products to feed people and provides basic ecological functions, ensuring the continuous operation of the material cycle while maintaining ecological balance. Among ecosystem types, agricultural ecosystems are considered to have a leading role for all communities in the world (Altieri, 2009). The SAN also gives out the solutions to minimize and compensate GHG emissions by carrying out the efficient and suitable management of fertilizers and pesticides, reducing the use of fossil fuels, and incorporating renewable energies into production systems (FAO, 2019). Other recommendations include promoting the diversification of agroecosystems to improve their adaptability to changing climate patterns; promoting crop residue incorporation, nitrogen fixation, and biological control strategies which can drastically reduce, if not eliminate, the need for emissions-intensive chemical inputs; encouraging soil management practices that contribute to yield while lowering the pressure of agricultural activities over soil resources; upgrading water use efficiency through better management skills that can reduce harmful impacts from changing conditions; promoting the use of weather monitoring systems and trends analysis in order to evaluate and reduce the risks of climate change; and evaluating livestock management processes to enable adaptation and a reduction of the systems' damages by climate variability. As such, agroecology and biological control have become the core features of SAN's sustainable agriculture and are formally recognized as low-carbon interventions.

\section{Models of sustainable agriculture in Vietnam}

Vietnam has several sustainable agricultural development models that are adaptable to climate change. This paper will focus on identifying two basic models: System of Rice Intensification (SRI) and Garden - Pond - Barn (GPB).

Farmers face a wide-range of problems that can cause reductions in the quality and quantity of their crops. These problems include the overuse of nitrogen fertilizer which reduces the resilience of rice plants, thereby making them susceptible to pests and attacks, and affects the quality of soil when the amount of fertilizer is redundant. Farmers also often rely on an excessive use of pesticides to increase resistance to pests. Complicated movements of climate change such as storms, floods, and droughts occur more and more frequently with great intensity, causing damages to crops, while the scarcity of water sources for living needs and farming production is becoming a problem. In addition, small-scale rice farmers often find it difficult to access agricultural extension models, they face price instability of input materials, and the revenue they earn is not enough to cover losses (Ministry of Agriculture and Rural Development, 2014).

To solve the above problems, and to ensure sustainability and efficiency in production, many organizations have implemented model projects to apply the improved SRI in Vietnam. Since being implemented as part of the Integrated Pest Management Program (IPM), SRI has brought success with the participation of local people and authorities.

Thus, the above model has shown flexibility and high sustainability for many reasons. The simple SRI technical principles are easy to implement and do not require high costs. Therefore, everyone can access SRI, especially the poor. SRI is an improved, flexible farming method suitable for all rice varieties, and depending on local conditions, the technical 
steps can be applied in part or in whole. This technique can be applied to all sizes of cultivation, so households with small arable land can also apply this technique. Socially, SRI receives support and the involvement of farmers, thanks to technical measures to help reduce hard labor days and reduce production costs.

The model also shows effectiveness in responding to climate change. Firstly, SRI helps to increase the resilience of rice plants to the abnormal events of weather due to climate change such as drought, storms, and epidemics. The rice grown under the SRI method has stronger stems and a deeper root system, which makes it less prone to lodging, and helps the plant absorb moisture and nutrients deeper in the soil. The pest resistance of rice plants is enhanced by the use of appropriate pesticides at the right frequency, in other words spraying less often and only applying one application at a time. This contributes to saving production investment costs but results in rice that still grows well and lacks pests. In addition, the amount of water used in cultivation is reduced compared to the traditional method of periodically draining 2-3 times per crop, helping people save irrigation water, especially when water is scarce. Secondly, SRI may contribute to minimizing greenhouse gases such as methane and nitrous oxide. $\mathrm{CH}_{4}$ gas is produced by anaerobic bacteria in the soil that lose oxygen due to frequent inundation. Therefore, regular draining of water in the field will significantly mitigate the amount of $\mathrm{CH}_{4}$ released into the atmosphere. In addition, the amount of $\mathrm{N}_{2} \mathrm{O}$ greenhouse gases is reduced by reducing the use of chemical fertilizers and using more efficient chemical fertilizers. According to estimates of the levels of greenhouse gas emissions when using organic fertilizers according to SRI, the pilot SRI fields have almost no increases in $\mathrm{N}_{2} \mathrm{O}$ emissions.

The purpose of developing the Garden Pond - Barn (GPB) model, according to the Ministry of Agriculture and Rural Development (2014), is to make the most of the land, terrain, water, and labor resources to improve the economic efficiency of farmers. As such, there is no standard model of crop and livestock structure in the GPB model. In order to have an effective
GPB model, it is necessary to have a structure of plants and animals suitable to the natural conditions (area, soil characteristics, topography, water sources, and climate, etc.) and social conditions (labor, markets, and transportation, etc.). The structures of plants and animals of each component in the model also depend on each other. For example, raising chickens and fish in a narrow garden area requires selecting species of trees with a less deciduous canopy cover and creating favorable conditions for the chickens and fish to grow.

The model is sustainable due to the use of indigenous knowledge in the development of the model, as most farm households already have knowledge in animal husbandry and cultivation, especially for crops and native poultry. In addition, non-key workers in the family such as the elderly, children, and women can also participate in the care of home-grown crops and livestock. This factor helps the model to be maintained even in households lacking a key labor force. It is also especially helpful with the current trend of young people wanting to leave the countryside to go to the big cities to look for job opportunities as they enter into adulthood.

The model is effective in adapting to and mitigating climate change. The GPB model is a diverse, sustainable sub-ecosystem, capable of generating self-resistance and has a high ability to be self-regulating for those who use it. Risks due to weather and market fluctuations are minimized in the GPB model, helping farmers have a relatively stable support system and reducing anxiety when the fields fail, as shown in the following points. For the garden aspect, adaptation to changes in climatic conditions such as saline intrusion and drought is managed through the selection of suitable plant varieties and cultivation techniques. Depending on the ecological region, the expansion of the garden and the expansion of afforestation can help to green bare hills, prevent erosion and landslides, prevent flying sand and jumping sand, shield waves, and contribute to water storage when digging fishponds. In hilly and mountainous areas, planting industrial crops and fruit trees such as tea, cassava, and peanuts help prevent erosion and landslides. In coastal areas, planting 
crops such as sweet potatoes, maize, soybean, or peanuts, combined with adjusting planting techniques such as using seed treatments, making high beds to cope with saline soils, adjusting the rate of fertilization, and using a variety of organic fertilizers that make use of manure or pond mud, instead of chemical fertilizers that cause greenhouse gas emissions $\left(\mathrm{N}_{2} \mathrm{O}\right)$, help increase sustainability. In addition, planting trees on sandy soil is important in preventing sand encroachment and desertification.

The pond aspect of the GPB model plays an important role, especially in saline soils, because of the effects of storing fresh water and rainwater. These "freshwater bags" within the farm households contribute to preventing saline water intrusion. In addition, they also save water for irrigation in drought conditions. The barn aspect helps mitigate pollution and emissions of $\mathrm{CH}_{4}$ gas into the atmosphere as well as minimizes the use of artificial fertilizers since animal waste is the main source of organic fertilizer for farming activities and fish food instead of traditional pesticides and herbicides.

The Garden - Pond - Barn model is a sustainable and flexible micro-ecological model that can be adapted to changing weather conditions by changing the structures of plants and animals. From an economic perspective, this model is meaningful in helping to reduce poverty and addressing the immediate needs of daily food for people. It is also considered an effective form of livelihood, enabling farmers to be self-reliant in agriculture production and improve their incomes.

\section{Conclusions}

Climate change is inevitable and is becoming increasingly serious, threatening all aspects of human life, and agriculture is one of the most seriously affected areas. In order to limit the damage to production, we are forced to find ways to adapt through appropriate cultivation methods. The goals of sustainable farming are to maximize the use of nature-based resources, increase production, and minimize the negative impacts of climate change without exacerbating damages to the environment. Depending on the objectives and conditions of each ecological region and each country, there are different sustainable farming strategies, but the common goal is to develop production methods that make global environmental protection a priority.

\section{References}

Altieri M. A. (2009). Agroecology, small farms, and food sovereignty. Monthly Review. 61(3): 102-113.

Institute of Meteorology, Hydrology and Climate Change (2018). The efects of sea-level rise on Vietnamese production Agriculture. Proceedings of the Conference on the effects of climate change on Vietnam Agriculture, October 2018 (in Vietnamese): 104-108.

FAO (2018). Yearbook, Sustainable to respond to climate change. DOI: 10.4060/cb1239en.

FAO (2019). Statistical pocketbook, Green house emission pp.42. ISBN: 98-92-5-131849-2. Retrieved from http://www.fao.org/3/cb1521en/CB1521EN.pdf on December 9, 2019.

FAO (2020). Yearbook, yearbook of fishery statistics. Retrieved https://www.foa.org/fi/oldsite/eim/317799 from December 2, 2019.

Javelinne D. (2014). The Most Important Topic Political Scientists Are Not Studying: Adapting to Climate Change. Perspectives on Politics. 12(2): 420-434. Retrieved from https://www.Jstor.org/43279918 on September 21, 2020.

Lincoln T. \& Eduardo Z. (1999). Photosynthesis: Physiological and Ecological Consideration. In: Lincoln T. \& Eduardo Z. (Eds.). Plant Physiology. The Benjamin/Cummings Publishing Company, Inc: 256257.

Ministry of Natural Resources and Environment (2014a). Practical of GHG in Vietnam . Unpublished report (in Vietnamese).

Ministry of Natural Resources and Environment (2014b). Vision of 2030, Method for reduction of $\mathrm{CO} 2$ emission. Unpublished report (in Vietnamese).

Ministry of Natural Resources and Environment (2017). Report on negative effects of climate change, Conference on the climate change in Vietnam, Hanoi 20th, January 2017 (in Vietnamese).

Ministry of Agriculture and Rural Development (2014). Organic Production in Hanoi. Workshop for Biomass Technology and Sustainable Agriculture, Hilton Hanoi Opera, 27th June 2014 (in Vietnamese).

Ministry of Agriculture and Rural Development (2018a). Yearly report of the damage by extremely climate in Vietnam. Proceedings of the Conference on the effects of climate change on Vietnam Agriculture, October, 2018 (in Vietnamese). 
Ministry of Rural Development and Agriculture (2018b). Biomass Potential, Opportinities and Chanlenge in Vietnam. Workshop on models for agriculture sustainable in Vietnam, Hanoi, September 20, 2018: 39-35 (in Vietnamese).

NASA (2014). Global Climate Change and Global Warming, Thomas Zurbuchen, Retrieved from https://scholar.google.com.vn/scholar?q=3.+NASA.+( 2014).+Global+Climate+Change+and+Global+Warm ing\&hl=vi\&as_sdt $=0 \&$ as_vis $=1 \&$ oi $=$ scholart on October 15, 2020.

NASA (2020). The negative effects of Climate Change on life Human, Susan Callery, June, 2020. Retrieved from https://scholar.google.com.vn/scholar?hl=vi\&as_sdt= $0 \% 2 \mathrm{C} 5 \&$ as_vis $=1 \& \mathrm{q}=5 . \% 09 \mathrm{NASA} .+\% 282020 \% 29$. + The+negative+effects + of + Climate + Change + on+life +Human \%2C+Susan+Callery\%2C+June\%2C+2020.+ $\& b t n G=$ on September 20, 2020.

Netherlands Environmental Assessment Agency (2015).
CO2 time series 1990-2014 per region/country. Retrieved from https://scholar.google.com.vn/scholar?hl=vi\&as_sdt= $0 \% 2 \mathrm{C} 5 \&$ as_vis $=1 \& \mathrm{q}=2 . \% 09 \mathrm{Netherlands+Environme}$ ntal+Assessment+Agency+\%282015\%29.+CO2+tim e+series+1990-2014+per+region\%2Fcountry\&btnG on November 15, 2020.

Shaffril H. A. M., Krauss S. E. \& Samsuddin S. F. (2018). A systematic review on Asian's farmers' adaptation practices towards climate change. Science of the Total Environment: 644: 683-695.

Sierra-Correa P. C. \& Kintz J. R. C. (2015). Ecosystembased adaptation for improving coastal planning for sea-level rise: A systematic review for mangrove coasts. Marine Policy. 51: 385-393.

Xiao Z. N., Li D. L., Zhou L. M., Zhao L. Z. \& Huo W. J. (2017). Interdisciplinary studies of solar activity and climate change. Atmospheric and Oceanic Science Letters. 10(4): 325-328. 